\title{
Talent Management and its Relationship to Career Stability among Academic Leaders at Al-Hussein Bin Talal University
}

\author{
Dima Waswas ${ }^{1} \&$ Mustafa Jwaifel12,* \\ ${ }^{1}$ Educational Administration, Faculty of Education, Al-Hussein Bin. Talal University, Jordan \\ ${ }^{2}$ Instructional Technology, Faculty of Education, Al-Hussein Bin. Talal University, Jordan \\ *Correspondence: Instructional Technology, Faculty of Education, Al-Hussein Bin. Talal University, Jordan. E-mail: \\ jwaifell@hotmail.com; jwaifell@ahu.edu.jo.https://orcid.org/0000-0002-7279-7253
}

Received: June 26, 2019 Accepted: July 24, 2019 Online Published: August 1, 2019

doi:10.5430/jct.v8n3p35 URL: https://doi.org/10.5430/jct.v8n3p35

\begin{abstract}
This study aimed to identify the level of applying talent management and achieving career stability among academic leaders at Al-Hussein Bin Talal University (AHU), and to investigate the relation between talent management and its domains with career stability. The study population consisted of all the (55) administrative academics in Al-Hussein Bin Talal University occupying positions: Dean, Vice Dean, and Head of Department. The analytical approach was used to develop the study tools and the descriptive approach to determine the level of applying talent management and the degree of career stability. To achieve the study objectives, two tools were used: applying talent management and achieving career satisfaction where its validity and reliability calculated. The results showed that means for talent management ranged between (3.236-3.448) with medium agreement; the highest among them was the domain of (talents acquisition), followed by the domain of (talents development), while the lowest was the talents maintenance domain. The total mean was (3.344) with a medium degree of agreement. The results also indicated that the means for the items of achieving career stability ranged between (3.218-4.273) with high and medium degrees of agreement, and the mean for the total was (3.82) with a high degree of agreement.
\end{abstract}

The results showed that correlation coefficients between the talent management and the career stability ranged between (0.685-0.799), which indicates that there is a positive relationship between them.

Keywords: talents management, career stability, al-hussein bin talal university

\section{Introduction}

Talent management is a relatively recent subject in the world of management. Attention to talents management was first drawn in the 1990s when the phrase "war of talent" caught up among major international corporations as an expression of intense competition among organizations. Thus, competition turned to attracting talented and highly-qualified people and providing regulatory and financial conditions that help maintain and keep them. It has also become a system applied in most of the institutions management as one of the development and change strategies (Radwan, 2013), for it is a process of attracting talented people's potentials to use them and disseminate them to others within the institution to achieve some common use of these potentials. (Sawa, 2017)

The rising tide of globalization, the increase of competition over individuals, and the migration of minds have led countries to pursue talents, and organizations have struggled to possess and employ talents and human intelligence to serve their objectives (Aljarah \& Abu Dawla, 2015). Therefore, officials dedicate (20\%-40\%) of their time to manage talents in their organizations, believing that talent is the best way to achieve competitive advantage; hence it must be maintained by setting a plan to manage talents from the time of recruitment until retirement age (Laff, 2006).

Talent management is one of the most effective strategies that forms an integral part of leadership development programs as they relate not only to career education, but to human relationships and human resource management (Radwan, 2013). Talent management is based on good choice, recruitment, guidance, performance management, career and leadership development, successive planning, and recognizing and reward talent (Bhatnagar, 2007).

Societies of different progress degrees attach great importance to the care of gifted and talented people for they 
possess outstanding abilities that must be pursued and developed. Excellence and talent are among the most important foundations of civilization progress and important factors in the progress of contemporary human beings and enhance their ability to face problems of their current life and future challenges (ALajez \& Murtaji, 2012).

Talent Management is defined as "the process of building and developing the abilities and talents of employees to achieve excellence and competition through carefully selecting, developing and training new employees, maintaining existing employees, and attracting talented and highly experienced people to work in business organizations" (Helal, 2010: 34).

(Sherif, 2009: 4) defines talent management as "the administrative procedures adopted within the organization in order to ensure the best attraction of individuals possessing unique abilities, skills and knowledge to work in the organization and then employ these capabilities of the individuals in order to maintain them for the sake of improving performance within the organization and influencing others through them."

It is also defined as "a set of integrated organizational processes designed to attract, manage, develop, motivate and retain key personnel in order to create a highly responsive organization with sustainable performance, supported by integrated and coherent automated systems that accomplish mutuality and integration among multiple strategic HR functions." (Abu Al-Jadael, 2013: 21)

The organization may obtain talent from two sources, either inside or outside the organization. And talents can be developed by giving everyone the freedom to show their distinctive ideas. Then, administration will discover creative individuals within departments and work to organize programs for training, educating and developing these individuals; which can never be achieved unless senior management supports this trend, or by attracting human talents. The most important factor to attract talents is to "develop the name and position of the organization," for what most helps attracting talented people is where the talent prefers to work. (JadAL_rap, 2009)

\section{Talent Management Domains}

Applying the different domains of talent management is a key factor for a successful implementation of talent management in the institution. These domains are the acquisition, development and maintenance of talented people:

Talents Acquisition: Acquisition can be defined as an administrative philosophy that the organization adopts to identify and attract the needed number and desired quality of the best qualified personnel for its vacant positions with selecting the best of them to achieve its competitive advantage (Khalifa, 2017). Thus, it is the process of choosing and recruiting talents, which proceeds by identifying the need talents and setting specific selection standards to select the best (Al-Smad, 2008). The process of acquisition also includes policies and practices through which talented individuals are selected and identified, where the focus is on the quality of competencies such as knowledge, skills, abilities and personality traits (Cheese, 2010).

Talent Development: Training programs for talented people focus on the enhancing competencies, skills and organizational values. These programs are based on performance evaluation to determine the training needs. The organization often relies on the talented to train the rest of its cadres because of their expertise that surpasses others' in addition to their ability to solve problems and adopt outstanding ideas and solutions; which helps solve the problem of costly training programs (Siam, 2013).

The process of talent development involves four phases: Identifying the employee who needs development, Designing a program for capacity development, and considering the time needed for this, Evaluating the tools used to measure the impact of talent development, and Identifying the organizational support provided by senior management (Garvan \& Carbery, 2012).

Talents Maintenance: Panoch $(2001,13)$ defined talents maintenance as "the set of policies and practices that make the human resource determine to stay in the organization for a long time."

Talents maintenance includes all activities that prevent talented people from leaving the organization (ALjarah \& Abu Dawla, 2015). Organizations recognize the need for keeping the talented employee as a basis for competition. The maintenance strategy consists of a combination of factors including compensation, rewards, performance management, fulfilling employees' needs, satisfying employees, preparing training programs, and the clarity of work strategies (Kermali, 2005).

Talents management seeks to achieve a set of administrative objectives including: 
1) Knowing the capabilities and roles associated with talent management, which are strategically important for developing a long-term plan to provide appropriate human resources (Jackso, Porteous, Gurel, \& Rushent, 2009).

2) Working to constantly provide talents in a matter that contributes to the competitive advantage of the institution. (Riccio, 2010)

3) Identifying the methods of attraction, selection and maintenance of personnel to achieve competition and success (Cannon \& McGee, 2010)

The importance of talent management is highlighted by focusing on strategically important and crucial career positions, identifying substitutes for position holderss, exploring potentials, avoiding disruption of work due to sudden departure of key position holders, and finally maintaining talents and ensuring their positive contribution to the foundation (Al-Humaidi \& Al-Tayeb, 2011).

\section{Career Stability}

Career stability is defined as "the good degree of adequacy available to guarantee workflow, stability and safety for the institution and its employees in a way that ensures the institution performance and not be subjected to fluctuations or various shocks" (Al-Deeb, 2006, 84).

It is also known as "the worker's having the greatest possibility of concentration in the work and not leaving it because of a range of guarantees provided by the institution represented in the financial, spiritual, social and psychological satisfaction of the worker" (Ben Mansour, 2014, 12).

Al-Sahaf $(1997,69)$ defines career stability as "the stability of the employee in his profession which appears through the rates of staying at work. Organizations measure the average of their employees' years of work to determine and stabilize career stability rates."

\subsection{Aspects of Career Stability}

Stability in work is one of the important things that play a great role in the effectiveness of performance and increasing the institution's productivity. Thus, the institution cannot achieve success without paying attention to human resources and keeping them from career loss, by providing all the conditions suitable for career stability, such as:

1. Unity of the working group: The organization is described as interacting groups, where each group has its own objectives and activities. Thus, cooperation and coordination among all these groups must be achieved to accomplish effective organization and career stability (Ben Mansour, 2014).

2. Psychological comfort and career security: The employee's feeling of reassurance about his permanence in work, his professional future, his health and his family and ensuring his decent living is considered an obsession that haunts him for the rest of his life. Accomplishing these demands is positively reflected in the performance of the employee because feeling secure is a condition for mental health (Alkheila, 2013).

3. Participating in decision-making: Everyone needs others' opinion for regardless of the educational qualification the individual cannot recognize all aspects of problems he faces, neither individually nor at the level of organization, or find solutions to those problems. Therefore, problems must be shared with others, since sharing is one of the most important foundations of management (Sfayani, 2012).

4. Managing and developing human resources: Managing labor force contributes to the formulation and rationalization of policies and programs of acquisition, selection, recruitment, planning, career development, training and promotion at the level of the organization. Hence, through the optimal use of human resources, the institution ensures a high degree of career satisfaction for employees (Zahani, 2016).

There are several manifestations of instability in work, including:

- Absence from work: Absence from work is a sign of the individual's lack of adaptation with the environment of his work, and an indication of tensions and resentment among workers. So, there is no doubt that the increase in absenteeism corresponds to cases of employee's hatred of the institution (Azion, 2007).

- Career rotation is to leave work for personal reasons such as wage system and internal promotion policies that contribute to the individual's decisions to leave work. In other words, the higher the organization's reputation is, the lower is employees' intention to leave work and if salaries and wages are high, and incentives are good and the 
opportunities for career progress are justly available to workers make the rate of leaving work low (Cole, M. \& Brush, H, 2006).

Career strike: It is a collective situation of employees to reject performing their duties without the intention of leaving their careers permanently, for the purpose of exerting pressure on the administration to achieve their professional demands (AL-Sarayra, 2012).

- Malingering: It is the pretence of sickness and justifying absence with illness reports without suffering a real trouble. This case spreads among workers who feel injustice and lack of adaptability to working conditions.

- Frequent complaints: Complaints are due to dissatisfaction with the general conditions of work, or as a result of the worker's feeling that he is not accepted by others, causing hatred of the work environment and an increase in the desire to leave the institution (Ben Mansour, 2014).

\section{Related Studies}

The study of Al-Hoshan (2017) aimed to identify the reality of implementing talent management strategies with school leaders in Riyadh. He used a descriptive surveying method. The study results indicated that school administrators annually faced difficulties in filling leadership positions. Furthermore, the study participants agree on the fact that increasing reliance on financial incentives encourages educational leaders to remain in their leadership positions.

(Al-jarah \& Abu Dawla, 2015) study aimed to identify the impact of talents management strategies on enhancing institutional affiliation. The study used descriptive analytical method, and the questionnaire was used to collect the data and was applied to a sample of (300) participants from Jordanian universities. The study concluded that the level of talent management in official Jordanian universities was medium, and that there was an important impact of the level of applying talent management strategies on the level of institutional affiliation.

The study of AL-Masri and AL-Aga (2015) aimed to provide a framework for applying the strategy of human talents management to achieve research excellence in the Palestinian universities in the light of knowledge society. The descriptive analytical approach was used, and the study was applied to a sample of 110 academic heads of departments in Palestinian universities in Gaza. Among the most important findings of the study is indicating a direct proportion between the level of applying the strategy of human talents management and achieving research excellence, as well as a direct proportion between the level of applying talent management and the formation of knowledge society, in addition to a direct proportion between forming knowledge society and achieving research excellence.

Ghazawi and Al-Ukeibi (2018) study aimed at clarifying the modern means of motivation in supporting workers' stability in their careers, by focusing on four main domains emphasized by most modern incentive programs and systems. The research concluded that the process of stimulating career stability is an integrated process that first requires providing conditions for giving incentives, and then the need for having full knowledge on the part of leaders about how to choose the best incentive for the case in hand, and finally stability is achieved when some materialistic and moral needs are satisfied.

The study of Combs, J. Edmonson, S. Jackson, S. (2009) aimed to explore the levels of career stability among elementary school principals Sam Houston State, USA. The study sample consisted of (228) managers and the descriptive analytical approach was used. The study results showed that $9 \%$ of the study sample suffered from career instability, and that career high spirit and satisfaction are high among managers who have a high level of stability.

Al-Assaf study (2006) aimed at revealing the level of career empowerment of leadership and its relation to the organizational commitment and voluntary career stability among faculty members in Jordanian public universities. The study community included (541) faculty members and the descriptive analytical method was used. The study results indicated that the level of practicing career empowerment among academic leaderships in Jordanian public universities was average and the level of career commitment and career stability among faculty members was high.

It can be noted from the above review of related studies on talent management shows that talent management is applied in educational institutions at a medium and high level. Moreover, there is a direct proportion between applying talent management and organizational affiliation and research excellence. Whereas, studies on career stability have confirmed that among the factors of career stability is the physical and moral motivation. 


\section{Method}

\subsection{Statement of the Problem}

The struggle among institutions to attract outstanding talents and qualifications has increased especially that human resources are able to move between institutions and countries as the impact of globalization and communication and information revolution increases. This shows the secret of excellence of institutions that succeed in attracting talents, for acquiring qualifications characterized by talent is considered as a competitive feature added to successful institutions.

Attracting talents is associated with work; so it's not only about attracting talents because it is possible that talented and qualified workers may move from the institution to other institutions. Therefore, it is significant for the institution to achieve career stability if it wants to maintain the existence of talents and competences. Thus, career stability is a state of adaptation and harmony in the work, and it is important to achieve success and reach the desired goals.

\subsection{The Study Questions}

1. What is the level of applying talent management among academic leaders at AHU?

2. Are there statistically significant differences at $(\alpha \leq 0.05)$ among the means of academic leaders' responses at AHU to the level of applying talent management according to the study variables (work position, years of experience, and place of work)?

3. What is the level of achieving career stability among academic leaders at AHU?

4. Are there statistically significant differences at $(\alpha \leq 0.05)$ among the means of academic leaders' responses at AHU to the level of achieving career stability according to the study variables (work position, years of experience, and place of work)?

5. Is there a statistically significant relationship at $(\alpha \leq 0.05)$ between the domains of talent management and career stability among academic leaders at AHU?

\subsection{The Study Significance}

1. The study examines talent management, a modern administrative subject of a great importance that has an impact on the progress and development of the institution.

2. The study tool is applied in a governmental educational institution, namely, AHU. It is hoped that its results will contribute to enhancing the process of attracting and developing talents in this university.

3. Hopefully, the study results and recommendations will have an impact on decision-makers in the Ministry of Higher Education to take decisions and procedures that will enhance talent management in higher education institutions.

4. The study examines the relationship between talent management and career stability, which are of a great importance in the managing educational institutions.

5. In the light of its results, the study presents a set of recommendations that contribute to enhancing the practice of talent management and career stability in universities.

\subsection{The Study Limitations}

1. Geography: AHU in Ma'an - Jordan.

2. Time: The second semester of the academic year 2018/2019.

3. Human: Academic managers at AHU who have administrative functions in addition to their duties as faculty members, including deans, vice-deans, heads of departments.

4. Study limitations: The study results are determined by the method of sample selection, the validity and reliability of the study tools, and the statistical procedures used to answer its questions.

\subsection{Procedural Definitions}

Talent Management: The administrative procedures taken within the university that work to attract human talents which are characterized by talent and excellence and seek to develop their capabilities and maintain the continuity of its work at the university, measured by the degree of the study participants' response to the study tool domains that are related to the aspects of talent management. 
Career stability: It is the academic leaders' sense of satisfaction and career security that motivates them to stay and continue to work. This is a voluntary choice resulting from a set of procedures taken by the university in order to achieve satisfaction and safety, measured by the degree of the study participants' response to the study tool domains related to career stability.

\subsection{The Study Sample and Population}

The study population consisted of (55) academic leaders at AHU, Deans, Vice Deans and Heads of Department. Thus, the study population is the sample itself. Table (1) shows the distribution of the participants according to preliminary data.

Table 1. Demographic Variables of the Sample

\begin{tabular}{llcc}
\hline Variables & \multicolumn{1}{c}{ categories } & Repetition & percentage \\
\hline \multirow{3}{*}{ Work position } & Dean & 11 & 20.0 \\
& Vice Dean & 10 & 18.2 \\
& Head of Department & 34 & 61.8 \\
\hline \multirow{3}{*}{ Years of experience } & 1-5 years & 14 & 25.5 \\
& 6-10 years & 21 & 38.2 \\
& 11 years and more & 20 & 36.4 \\
\hline \multirow{3}{*}{ Place of work } & Collages of Arts and Humanity Sciences & 26 & 47.3 \\
& Scientific Collages & 25 & 45.5 \\
& Others & 4 & 7.3 \\
\hline & Total & 55 & 100.0 \\
\hline
\end{tabular}

Table (1) shows the following:

1. The highest percentage of the sample distribution according to work position variable was $(61.8 \%)$ for the work title (Head of Department), while the lowest percentage (18.2\%) was for the work title (Vice Dean).

2. The highest percentage of the sample distribution according to years of experience variable was (38.5\%) for (6-10 years), while the lowest percentage (25.5\%) was for (1-5 years).

3. The highest percentage of the sample distribution according to the place of work variable was (47.3\%) for (Colleges of Arts and Humanity), while the lowest percentage (7.3\%) was for the (others).

\subsection{Measurement Tools}

To achieve the study objectives, two tools were used: the first was to measure the level of applying talent management, and the second was to measure the level of achieving work satisfaction. Previous researches and studies have been analyzed and explored to determine the domains and items of the study tools. Thus, the study of (Al-Masri, Al-Aga, 2015; AL-jarah; Abu Dawla, 2015) was used to develop the talent management tool, and the study of (Al-Assaf, 2006) was used to develop the career stability tool.

\subsubsection{Validity}

The domains of the study tools were developed and presented to a group of referees of university professors to extract the sincerity of the arbitrators, to check the linguistic structure of the classification under their appropriate domains, and their suitability to achieve the study objectives. The necessary amendments have been made in the light of the arbitrators' observations. Also, the indicators of the study tools validity were calculated by calculating correlation coefficient of each item under its domain and to the total under which it is categorized. It was concluded that all the items of the two tools were statistically significant.

\subsubsection{Reliability}

Reliability verified during applying the study by using Cronbach Alpha determine the coefficient of the internal consistency of the items of talent management tool and career stability tool, as shown in table (2): 
Table 2. Reliability Coefficient

\begin{tabular}{lc}
\hline \multicolumn{1}{c}{ Tools } & Cronbach Alpha \\
\hline Talent Acquisition & 0.876 \\
Talents Development & 0.944 \\
Talents Maintenance & 0.935 \\
Talents Management & 0.963 \\
Career Stability & 0.84 \\
\hline
\end{tabular}

Table (2) shows that the values of validity coefficients for both tools are high and fair for the study purposes.

\subsection{Methodology}

The analytical approach was used to develop the study tools, and the descriptive approach to investigate the level of applying talent management and the degree of career stability, according to the following study variables:

Work position: Dean, Vice Dean, Head of Department.

Years of Experience: 1-5 years, 6-10 years, 11 years and above.

Place of work: College of humanity, Scientific college, Others.

Measured variables: Level of talent management (talents acquisition, talents development, talents maintenance), level of career stability.

\subsubsection{Statistical Procedures}

The following statistical procedures were used to answer the study question:

1. Using measures of dispersion and measures of central tendency.

2. Using percentages and internal consistency coefficient (Cronbach Alpha).

3. Using correlation coefficient (Pearson).

4. Using multivariate analysis of variance (MANOVA).

\subsubsection{Procedures}

The following procedures were used to achieve the study objectives:

1. Reviewing previous literature and developing the measurement tools.

2. Ethics concerning formal approvals for conducting the research.

3. Distributing the research tools and then collecting them, and using (SPSS) program for data entry.

4. Conducting the necessary statistical analysis and procedures to conclude the results.

\section{Results and Discussion}

This section presents the results of the study that aimed at identifying the level of talent management and the level of career stability and the relationship between them. The following is a presentation of the study results according to the questions.

\section{Question One: What is the level of applying talents management among academic leaders at AHU?}

To answer this question, means and standard deviations of talent management domains were calculated, as shown in tables (3):

Table 3. Means and Standard Deviations of Talents Management Domains in a Descending Order According to Means

\begin{tabular}{clccc}
\hline No. & Domain & Mean* & SD & Degree \\
\hline 1 & Talents Acquisition & 3.448 & .5180 & Average \\
2 & Talents Development & 3.305 & .6750 & Average \\
3 & Talents Maintenance & 3.236 & .6560 & Average \\
& Talents Management & 3.344 & .5600 & Average \\
\hline
\end{tabular}


As shown in Table (3), the means of talent management ranged between (3.236 - 3.448) with an average degree of approval. The highest mean was for talent acquisition $(\mathrm{M}=3.448, \mathrm{SD}=0.518)$, followed by talents development $(\mathrm{M}=3.305, \mathrm{SD}=0.675)$, while the lowest was for talents maintenance $(\mathrm{M}=3.036, \mathrm{SD}=0.656)$. The total of talents management was in average degree $(\mathrm{M}=3.344, \mathrm{SD}=0.560)$.

This result was consistent with the result of Al-Jarah and Abu Dawla (2015) study in that the level of applying talents management in Jordanian public universities was average. Whereas, it contrasted with the result of Al-Masri and AL-Aga (2015) study which indicated that the level of applying talent management in Palestinian universities was high.

This result can be explained by the fact that AHU implements some procedures that contribute to attracting, developing and maintaining talents. The university seeks to create a distinguished position among universities by attracting talented cadres that seek to achieve quality, open different disciplines and achieve academic accreditation standards.

\section{Domain One: Talents Acquisition:}

Table 4. Means and Standard Deviations of Talents Acquisition Items

\begin{tabular}{cllcc}
\hline No. & \multicolumn{1}{c}{ Items } & Mean* & SD & Degree \\
\hline $\mathbf{6}$ & $\begin{array}{l}\text { The university strives to gain a prestigious position among universities by attracting talented } \\
\text { competences. }\end{array}$ & 3.818 & .7960 & High \\
$\mathbf{5}$ & $\begin{array}{l}\text { The methods of employees selection are transparent in that their principles of selection and } \\
\text { results are announced publically. }\end{array}$ & 3.800 & .7300 & High \\
$\mathbf{3}$ & $\begin{array}{l}\text { The university announces its careers needs in all ways to attract the largest number of talented } \\
\text { people. }\end{array}$ & 3.709 & .8540 & High \\
$\mathbf{8}$ & The university recruits talented students to study and then work for it. & 3.655 & .9270 & High \\
$\mathbf{9}$ & Priority to recruitment is given to employees with distinct qualifications and experiences. & 3.545 & .9390 & Average \\
$\mathbf{7}$ & The university encourages creative initiatives that highlight its talented employees. & 3.527 & .6630 & Average \\
$\mathbf{4}$ & The methods of staff selection are based on objectivity that depends on clear criteria. & 3.491 & .8580 & Average \\
$\mathbf{1}$ & The university relies on the criterion of competence in selecting its employees. & 3.473 & .5040 & Average \\
$\mathbf{1 2}$ & The university plans to identify its current and future needs in an organized manner. & 3.418 & .8960 & Average \\
$\mathbf{1 1}$ & The university believes that talent acquisition is the perfect way to encourage competition. & 3.309 & .7170 & Average \\
$\mathbf{2}$ & The university looks for talented people and acquires them to work for it. & 3.182 & .6410 & Average \\
$\mathbf{1 0}$ & The university's financial level is a source of attraction for outstanding competencies. & 2.455 & .8990 & Average \\
\hline
\end{tabular}

Table (4) shows that the means of talents acquisition ranged between (2.455-3.818) with high and average degrees of approval. The highest mean was for item (6) "the university seeks to gain a distinguished position among universities by attracting talented competences" $(\mathrm{M}=3.818, \mathrm{SD}=0.796)$, followed by the for item (5): methods of employees selection are transparent in that their basis of selection and results are announced publically $(\mathrm{M}=3.80, \mathrm{SD}=0.73)$, while the lowest was for item (10): The university's financial level is a source of attraction for outstanding competencies $(\mathrm{M}=2.455, \mathrm{SD}=0.899)$.

The results indicate that the field of talents acquisition has received an average degree of practice. And the items that refer to how the university seeks to gain a distinguished position among universities, the transparency of employees selection methods, and the university's announcement for its career needs a high level of practice. This result indicates that AHU seeks to attract talents through applying the principle of transparency and objectivity in advertising and selection. The item "the university's financial level is a source of attraction for outstanding competencies" had the lowest mean which indicates that the financial level at AHU is lower than the level of income in other public universities. 


\section{Domain Two: Talents Development:}

Table 5. Means and Standard Deviations of Talents Development Items

\begin{tabular}{|c|c|c|c|c|}
\hline No. & Items & Mean & SD & Approval Degree \\
\hline 14 & Faculty members are promoted based on excellence in scientific and research aspects. & 4.055 & .7050 & High \\
\hline 17 & The university supports and motivates distinctive researchers. & 3.764 & .7690 & High \\
\hline 16 & $\begin{array}{l}\text { The university provides employees with training opportunities outside the university } \\
\text { through conferences and training workshops. }\end{array}$ & 3.636 & .8900 & Average \\
\hline 15 & The university constantly arranges training programs. & 3.291 & .8750 & Average \\
\hline 13 & The university seeks to identify its employees' training needs. & 3.255 & .8860 & Average \\
\hline 18 & The university empowers qualified people to hold leadership positions. & 3.145 & .7560 & Average \\
\hline 20 & The university encourages talented members to train their colleagues. & 3.091 & .8450 & Average \\
\hline 22 & $\begin{array}{l}\text { The university gives talented employees the opportunity to develop work methods by } \\
\text { themselves. }\end{array}$ & 2.982 & .8710 & Average \\
\hline 19 & $\begin{array}{l}\text { Employees participate in setting a training plan to be developed functionally and } \\
\text { professionally. }\end{array}$ & 2.927 & .8790 & Average \\
\hline 21 & The university allocates a specific budget for the development of talented employees. & 2.909 & .7760 & Average \\
\hline & Total: Talents Development & 3.305 & .6750 & Average \\
\hline
\end{tabular}

Table (5) shows that the means of talent development area ranged between (2.909 - 4.055) with high and average degrees of approval, where the highest was for item (14) "faculty members are promoted based on excellence in scientific and research aspects" (M4.055, $\mathrm{SD}=(0.705)$, followed by item (17) "the university supports and motivates distinctive researchers" $(\mathrm{M}=3.764, \mathrm{SD}=0.769)$, while the lowest was for item (21), "the university allocates a specific budget for the development of talented employees" ( $\mathrm{M}=2.909,0.776)$.

It is worth noting that AHU practices talent development through providing training opportunities and empowering competences to hold leadership positions in an average degree. The two items which indicate that faculty members are promoted according to their excellence in research and that the university supports distinctive researchers have received a high degree. This is an indication of having clear and well-identified standards for faculty members' promotion, that are applied to everyone, and that the university heads for supporting faculty members who publish in refereed global journals.

The item indicating that the university allocates a specific budget for the development of talented employees received the lowest mean because of the limited funding sources for the university and this makes it go through a financial crisis that limits their development projects for workers.

\section{Domain Three: Talents Maintenance:}

Table 6. Means and standard Deviations of Talents Maintenance Items in a Descending Order According to Means

\begin{tabular}{|c|c|c|c|c|}
\hline No. & Items & Mean & SD & Approval Degree \\
\hline 24 & The university seeks to constantly develop teaching programs. & 3.709 & .6850 & High \\
\hline 23 & The university provides an excellent environment for scientific research. & 3.327 & .6400 & Average \\
\hline 30 & $\begin{array}{l}\text { The university seeks to eliminate causes of career tension and increase motivation for } \\
\text { achievement. }\end{array}$ & 3.273 & .7810 & Average \\
\hline 27 & The University seeks to fill administrative academic vacancies with talented faculty members. & 3.255 & .7750 & Average \\
\hline 25 & The University offers various incentives for talented employees. & 3.200 & .8030 & Average \\
\hline 28 & The University assigns the task of leading innovative projects for talented people. & 3.164 & .8980 & Average \\
\hline 26 & $\begin{array}{l}\text { The university provides faculty members with all available materials to stimulate their career } \\
\text { stability. }\end{array}$ & 2.982 & .7820 & Average \\
\hline 29 & $\begin{array}{l}\text { The University provides services related to health insurance and housing for qualified } \\
\text { employees. }\end{array}$ & 2.982 & .9330 & Average \\
\hline & Total: Talents Maintenance & 3.236 & .6560 & Average \\
\hline
\end{tabular}


Table (6) shows that the means for talents maintenance items ranged from (2.982 - 3.709) with high and average degrees of approval, where the highest was for item (24) "the university seeks to constantly develop teaching programs" (M3.709, $\mathrm{SD}=(0.685)$, followed by the item (23) university provides an excellent environment for scientific research" $(\mathrm{M}=3.327, \mathrm{SD}=0.640)$, while the lowest was for item (29) "the university provides services related to health insurance and housing for qualified employees" $(\mathrm{M}=2.982, \mathrm{SD}=0.933)$.

Based on the results above, it can be said that talents maintenance has received an average degree of practice. All its items have reached an average level of practice; except for the item indicating that the university seeks to constantly develop training programs was of a high degree. This indicates that there are continuous development plans for teaching programs in the academic departments.

Question Two: Are there statistically significant differences at $(\alpha \leq 0.05)$ among the means of academic leaders' responses at $\mathrm{AHU}$ to the level of applying talent management according to the study variables (work position, years of experience, and place of work)?

To answer this question, a multivariate analysis of variance (MANOVA) was used to calculate the differences between the means of the participants' responses on talent management domains according to the study variables (work position, years of experience and place of work), as shown in table (7):

Table 7. Results of MANOVA Analysis of $t$ Talent Management Domains

\begin{tabular}{|c|c|c|c|c|c|c|}
\hline & Variable & & $\begin{array}{c}\text { Talents } \\
\text { Acquisition }\end{array}$ & $\begin{array}{c}\text { Talents } \\
\text { Development }\end{array}$ & $\begin{array}{c}\text { Talents } \\
\text { Maintenance }\end{array}$ & Total \\
\hline \multirow{6}{*}{ Work Position } & \multirow{2}{*}{ Dean } & Mean & 3.205 & 3.209 & 3.182 & 3.200 \\
\hline & & Standard Deviation & .539 & .470 & .549 & .499 \\
\hline & \multirow{2}{*}{ Vice Dean } & Mean & 3.658 & 3.650 & 3.613 & 3.643 \\
\hline & & Standard Deviation & .436 & .438 & .576 & .445 \\
\hline & \multirow{2}{*}{$\begin{array}{c}\text { Head of } \\
\text { Department }\end{array}$} & Mean & 3.466 & 3.235 & 3.143 & 3.303 \\
\hline & & Standard Deviation & .515 & .763 & .685 & .589 \\
\hline \multirow{6}{*}{$\begin{array}{c}\text { Years of } \\
\text { Experience }\end{array}$} & \multirow{2}{*}{ 1-5 years } & Mean & 3.440 & 3.507 & 3.277 & 3.419 \\
\hline & & Standard Deviation & .638 & .726 & .711 & .664 \\
\hline & \multirow{2}{*}{ 5-10 years } & Mean & 3.512 & 3.157 & 3.179 & 3.305 \\
\hline & & Standard Deviation & .460 & .745 & .729 & .574 \\
\hline & \multirow{2}{*}{11 years and above } & Mean & 3.388 & 3.320 & 3.269 & 3.333 \\
\hline & & Standard Deviation & .502 & .544 & .558 & .485 \\
\hline \multirow{6}{*}{ Place of Work } & \multirow{2}{*}{ Humanity Collage } & Mean & 3.455 & 3.419 & 3.279 & 3.396 \\
\hline & & Standard Deviation & .354 & .569 & .626 & .449 \\
\hline & \multirow{2}{*}{ Scientific Collage } & Mean & 3.390 & 3.156 & 3.110 & 3.237 \\
\hline & & Standard Deviation & .669 & .792 & .703 & .675 \\
\hline & \multirow{2}{*}{ Others } & Mean & 3.771 & 3.500 & 3.750 & 3.675 \\
\hline & & Standard Deviation & .172 & .383 & .177 & .222 \\
\hline
\end{tabular}

As shown in table (8), there are no statistically significant differences at $(\alpha \leq 0.05)$ between the means of the participants' responses on the domains of talent management according to the study variables (work position, years of experience and place of work).

Responses of the participants are consistent among each other on the degree of talent management practice regardless of the work position, years of experience or place of work, which indicates that the administrative procedures related to talent management are clear to everyone. Furthermore, the domains of talent management affect all employees, whether in the process of attracting, developing, or maintaining talents. 
Table 8. Results of MANOVA Analysis of the Differences between Talent Management Domains

\begin{tabular}{|c|c|c|c|c|c|c|}
\hline Source of Variance & Domain & Sum of Squares & D.F & Mean Squares & $\mathbf{F}$ & Sig. \\
\hline \multirow{4}{*}{ Work Position } & Talents Acquisition & .933 & 2 & .467 & 1.765 & .182 \\
\hline & Talents Development & 1.732 & 2 & .866 & 1.995 & .147 \\
\hline & Talents Maintenance & 1.356 & 2 & .678 & 1.607 & .211 \\
\hline & Total Domains & 1.052 & 2 & .526 & 1.701 & .193 \\
\hline \multirow{4}{*}{$\begin{array}{c}\text { Years of } \\
\text { Experience }\end{array}$} & Talents Acquisition & .030 & 2 & .015 & .056 & .946 \\
\hline & Talents Development & 1.377 & 2 & .689 & 1.586 & .215 \\
\hline & Talents Maintenance & .252 & 2 & .126 & .299 & .743 \\
\hline & Total Domains & .223 & 2 & .112 & .361 & .699 \\
\hline \multirow{4}{*}{ Place of Work } & Talents Acquisition & .615 & 2 & .307 & 1.163 & .321 \\
\hline & Talents Development & .786 & 2 & .393 & .906 & .411 \\
\hline & Talents Maintenance & .975 & 2 & .487 & 1.155 & .324 \\
\hline & Total Domains & .622 & 2 & .311 & 1.006 & .373 \\
\hline \multirow{4}{*}{ Error } & Talents Acquisition & 12.686 & 48 & .264 & & \\
\hline & Talents Development & 20.840 & 48 & .434 & & \\
\hline & Talents Maintenance & 20.251 & 48 & .422 & & \\
\hline & Total Domains & 14.843 & 48 & .309 & & \\
\hline
\end{tabular}

Question Three: What is the level of achieving career stability among academic leaders at AHU?

To answer this question, means and standard deviations of career stability items were calculated, as illustrated in tables (9):

Table 9. Means and Standard Deviations of Career Stability Items in a Descending Order

\begin{tabular}{|c|c|c|c|c|}
\hline No. & Items & Mean & SD & Approval Degree \\
\hline 6 & $\begin{array}{l}\text { I am ready to make an additional effort that helps my university to achieve success and } \\
\text { excellence. }\end{array}$ & 4.273 & 0.560 & High \\
\hline 9 & I do any work assigned to me without complaint. & 4.255 & 0.584 & High \\
\hline 7 & I feel secure in my career as a result of my stay at work. & 4.091 & 0.398 & High \\
\hline 3 & I seek a distinctive work position at work. & 4.036 & 0.470 & High \\
\hline 4 & My personal values are consistent with the work values. & 3.964 & 0.666 & High \\
\hline 1 & $\begin{array}{l}\text { I prefer to stay in my work despite the availability of work opportunities in other } \\
\text { institutions. }\end{array}$ & 3.618 & 0.707 & Average \\
\hline 2 & My work provides me with opportunities for career development. & 3.545 & 0.812 & Average \\
\hline 8 & Continuing in work contributes to achieving rewarding financial gains. & 3.382 & 0.805 & Average \\
\hline 5 & Work offers me privileges that are not available in other work. & 3.218 & 0.809 & Average \\
\hline & Total: Achieving Career Stability & 3.820 & 0.438 & High \\
\hline
\end{tabular}

Table (9) shows that means career stability ranged between (3.218-4.273) with high and average degrees of approval, where the highest was for item (6) "I am ready to make an additional effort that helps my university to achieve success and excellence" ( $M=4.273$. SD0.560), followed by the item (9) "I do any task assigned to me without complaint" ( $\mathrm{M}=4.255, \mathrm{SD}=0.584)$, while the lowest was for item (5) "work offers me privileges that are not available in other work" $(\mathrm{M}=3.82, \mathrm{SD}=0.584)$. The total mean reached (3.82) and a standard deviation (0.438) with a high degree of approval.

This finding coincided with the study of Assaf (2006) that the level of career stability among faculty members in Jordanian universities was high. This result is explained by the fact that academic leaders believe that the level of career stability is high because of the sense of satisfaction and career security that motivates employees to stay in work $t$ the university. This is attributed to their willingness to make any extra effort that helps the university achieve success and excellence; they are also ready to do any work assigned to them, in addition to their sense of career security, seeking to obtain a distinguished work rank, and the compatibility of their personal values with the values 
of work.

Question Four: Are there statistically significant differences at $(\alpha \leq 0.05)$ among the means of academic leaders' responses at AHU to the level of achieving career stability according to the study variables (work position, years of experience, and place of work)?

To answer this question, multivariate analysis of variance was used to calculate the differences between the means of the participants' responses to career stability according to the study variables (work position, years of experience and place of work), as shown in table (10):

Table 10. Means and Standard Deviations of Career Stability According Work Positions

\begin{tabular}{lccc}
\hline Variable & & Mean & Standard Deviation \\
\hline \multirow{4}{*}{ Work Position } & Dean & 3.576 & .361 \\
& Vice Dean & 4.033 & .363 \\
& Head of Department & 3.837 & .452 \\
\hline \multirow{3}{*}{ Years of Experience } & $1-5$ years & 3.881 & .614 \\
& $5-10$ years & 3.862 & .375 \\
& 11 years and above & 3.733 & .356 \\
\hline \multirow{3}{*}{ Place of Work } & Humanity Collage & 3.850 & .400 \\
& Scientific Collage & 3.782 & .511 \\
& Others & 3.861 & .106 \\
\hline
\end{tabular}

Table 11. MANOVA analysis of the differences of career stability

\begin{tabular}{lccccc}
\hline Source of Variance & Sum of Squares & D.F & Mean Square & F & Sig. \\
\hline Work Position & .837 & 2 & .418 & 2.202 & .122 \\
Years of Experience & .022 & 2 & .011 & .058 & .944 \\
Place of Work & .093 & 2 & .046 & .244 & .784 \\
Error & 9.121 & 48 & .190 & & \\
\hline
\end{tabular}

Based on the previous table (11), there are no statistically significant differences at $(\alpha \leq 0.05)$ between means of the participants' responses on career stability scale according to the study variables (work position, years of experience and place of work).

This result indicates that the level of career satisfaction does not differ according to the study variables, which is an indication that the factors of career satisfaction are available to all academic leaders regardless of their work position, years of experience and colleges, and this indicates that AHU seeks to achieve the factors of career satisfaction for all employees.

Question Five: Is there a statistically significant relationship at $(\alpha \leq 0.05)$ between the domains of talent management and career stability among academic leaders at AHU?

To answer this question, Pearson correlation coefficients were extracted between the domains of talent management and career stability, as shown in table (12):

Table 12. Pearson Correlation Test between Domains of Talent Management and Career Stability

\begin{tabular}{rcccc}
\hline Domains & Talents Development & Talents Maintenance & Talents Management & Career Stability \\
\hline Talents Acquisition & $.668^{* *}$ & $.754^{* *}$ & $.874^{* *}$ & $.788^{* *}$ \\
Talents Development & & $.919^{* *}$ & $.936^{* *}$ & $.685^{* *}$ \\
Talents Maintenance & & & $.961^{* *}$ & $.742^{* *}$ \\
Talents Management & & & $.799^{* *}$ \\
\hline
\end{tabular}

Based on the above table, the correlation coefficients between talent management and career stability ranged between (0.685-0.799), indicating a direct proportion between talent management and career stability.

This finding was consistent with the study of Al-Jarah and Abu Dawla (2015) which showed a positive and direct 
correlation with the level of applying talent management strategies with the level of organizational affiliation.

This result explains that the achieving talent management with its domains of talents acquisition, talents development, and talents maintenance has a direct proportion with achieving career stability among academic leaders at AHU. This result is quite logical since applying talent management through attracting competent and experienced employees, providing improvement and training opportunities for employees and as well as support and motivation for distinguished researchers, empowering qualified employees to hold administrative and leadership positions, and the university's efforts to provide a distinct academic research atmosphere are all factors that contribute to having career satisfaction, security, and stability among workers. Thus, it is noted that applying talent management elements directly contributes to achieving career stability.

\section{Conclusion and Recommendations}

The finding of this study revealed a logical since in applying career stability among academics leaders in universities when achieving talent management. Based on this major finding the study recommended:

- Transforming faculty development centers within the university into centers of talents industry.

- Developing a method to evaluate faculty members to discover talents and recruit them in the right place.

- Establishing bases for recruitment and selection in universities that rely on the criteria of talents acquisition.

- Taking advantage of talented instructors' sabbatical and work to move them among different universities to transfer their experience to other universities.

- Applying modern educational management trends in the field of talent management and expand the culture of talent management to all educational institutions.

- Providing learning supplies like laboratories, tools, libraries, communication devices and for faculty members to develop their abilities and talents.

- Establishing a national center concerned with scientific research and providing incentives to support distinguished researchers.

- Empowering highly qualified cadres for leadership positions in universities.

- Providing the perfect conditions to attract talented faculty members to recruit them in universities and reduce immigration and the tendency to work outside Jordan.

- Granting talented faculty members financial and moral incentives regularly.

- Creating an atmosphere of competition, development and training within universities through competitions related to scientific research, teaching quality and community service.

- Supporting career stability in universities, including improving income level, providing career security factors, providing opportunities for promotion at work, and providing opportunities for profession growth.

\section{References}

Abu Al-Jadael, Hatem. (2013). Talent Management. Cairo, Center for Professional Experience of Management.

Al - Hoshan, Mamdouh. (2017). The reality of Applying Talent Management Among School Leaders in Riyadh City. Fayoum University Journal of Educational and Psychological Sciences, No. 7, Part III.

AL- Sarayra, Ibrahim. (2012). Legitimacy of Strike and Its Impact on Contractual Relations, Comparative Study, Dar Wael for Publishing and Distribution, Jordan.

ALajez, Fuad \& Murtaji, Zaki. (2012). The Reality of Talented and Gifted Students in Gaza Governorate and Ways to Improve it. Journal of the Islamic University for Educational and Psychological Studies, 20(1).

Al-Deeb, Ibrahim. (2006). Manual of Human Resources Management. Cairo: Umm Al-Qura Foundation for Translation, Publishing and Distribution.

Al-Humaidi, Mohammed \& Al-Tayeb, Al-Hadi. (2011). Investment in Training and Talent Management: UAE Experience. Research Paper, Al Shorfa College, Officers Training Institute Ras Al Khaimah, United Arab Emirates.

AL-Jarrah, Saleh \& Abu Dawla, Jamal. (2015). The Impact of Applying Talent Management Strategies in Enhancing 
the Organizational Affiliation among Faculty Members in Jordanian Public Universities. The Jordanian Journal of Business Administration, 11(2), 283-315.

Alkheila, Aisha. (2013). The Impact of Career Security on the Performance of the Worker Within the Institution, Unpublished Master thesis, University of Msela, Algeria.

AL-Masri, Nidal, AL- Aga, Mohamed. (2015). Management of Human Talents in Palestinian Universities: A Proposal for Developmental Strategic Application. Research presented to the Fourth Conference of Social Human Sciences, Arab Center for Research and Policy Studies, Marrakech, 19-21 March 2015.

Al-Smadi, Nasim. (2008). Talent Management, Journal of Manager and Businessmen's Books, 363. Arab Company for Scientific press: Shuaa, Cairo.

Assaf, Hussain. (2006). Career Empowerment among Academic Leaders in Jordanian Public Universities and Its Relation to Organizational Commitment and Voluntary Career Stability among Its Teaching Staff Members. Unpublished Master Thesis, Amman Arab University, Jordan.

Azion, Zehia. (2007). Motivation and Its Impact on Job Satisfaction of the Human Resource in the Economic Institution. Unpublished Master Thesis, University of Skika, Algeria.

Ben Mansour, Rafika. (2014). Career stability and its Relation to the Performance of Workers in the Private Sector. Unpublished Master Thesis, University of Haj Lakhdar, Algeria.

Bhatangar. J. (2007). Talent Management Strategy of Employee Engagement in India itesenployees (Key to retention). Emerald group publishing limited, India, p641.

Cannon James A., \& Rita McGee. (2010). Talent Management and Succession Planning (2nd Ed.). Chartered Institute of Personnel and Development, www.cipd.co.uk/bookstore.

Cheese, P. (2010). Talent Management for a New Era: What We Have Learned From Recession and What We Need to Focus on Next. Human Resource Management International Digest, 18(3), 3-5. https://doi.org/10.1108/09670731011040281

Cloe, M., \& Bruch, H. (2006). Organizational Identity Strength, Identification, and Commitment and Their Relationships to Turnover Intention: Does Organizational Hierarchy? Matter Journal of Organization behavior, 27, 585-605. https://doi.org/10.1002/job.378

Combs, J., Edmonson, S., \& Jackson, S. (2009). Burnout Among Elementary School Principals. AA.SA Journal of Scholarship and Practice, 5(4), 10-15.

Garvan, T. N., Carbeny, R., \& Rock, A. (2012). Mapping Talent Development: Definition Scope and Architecture. European Journal of Training and Development, 36(1), 5-24. https://doi.org/10.1108/03090591211192601

Ghazawi, Hamza, Al-Ukeibi \& Al-Azhar. (2018). Stimulating Job Stability (Methods, Successful Models). Journal of Scientific Horizons, 10(2), 79-97.

Helal, Mohamed. (2010). Talent Management, Talent and Investment in Human Resources. Cairo: Performance Development and improvement Center.

Jackso, W. S., Porteous, A., \& Gurel, O., \& Rushent, C. (2009). Emirati Talent Management: Effective Nationalization Oxford Strategic Consulting Gulf.

Jad AL-rab, Sayed. (2009). Contemporary Trends in Human Resource Management. Dar Al-Feker Al-Arabi, Egypt.

Kermali, Sultan. (2005). Knowledge Management: An Application Introductory, Translated by Haitham Megazi, Amman, Alahliya for Publishing and Distribution.

Khalifa, Mohamed. (2017). The Effect of Talent Management on Achieving Creativity in Kuwaiti Commercial Banks. Unpublished Master Thesis, Al-Bayt University.

Laff, M. (2006). Talent Management: From Hire to Retire. TANDD, 60(11), 39-45.

Panoch, A. (2001). The Relationship between Pivesity and Employee Retention. Master's Thesis, University of Wisconsin State, Menomonie.

Radwan, Mahmoud. (2013). Talent Management in the Organization. Arab Group for Training and Publishing, Cairo, Egypt.

Riccio S. (2010). Talent Management in Higher Education: Identifying and Developing Emerging Leaders Within the Administration at Private Colleges and Universities. PH.D Dissertation, the University of Nebraska- 
Lincoln Nebraska, United States.

Sahaf, Habib. (1997). Glossary of Human Resources and Personnel Management, Arabic English 1. Lebanon Library: Beirut Lebanon Publishers.

Sawa, Rawia. (2017). The Impact of the Talent Management Strategy in Achieving Excellence in the Foundation, the Case Study of Nqawas Mineral Water Foundation. Unpublished Master Thesis, University of Mohammed Khudair, Algeria.

Sherif, Rajab. (2009). Management of Leadership Talents in the Educational Institution. The Forum of Creativity and Administrative Excellence, Doha, Qatar, 8/3/2008.

Siam, Aziza. (2013). The Reality of Applying Human Talent Management System From the Viewpoint of Middle and Upper Management, the Case Study of the Islamic University in Gaza.

Sufyani, Majid. (2012). The Degree of Teachers Participation in School Decision-Making. Unpublished Master Thesis, Umm al-Qura University.

Zahani, Wisam. (2016). Incentives System and Stability of the Human Resource in the Algerian Institution. Unpublished Master Thesis, University of Mohammed Khiedr. 